\title{
Highly Efficient Biphasic System for the Synthesis of Alkyl Lactates in the Presence of Acidic Ionic Liquids
}

\author{
Urszula Dorosz $^{1}$, Natalia Barteczko ${ }^{2}$, Piotr Latos ${ }^{2}{ }^{\circledR}$, Karol Erfurt $^{2}{ }^{\circledR}$, Ewa Pankalla ${ }^{1}$ \\ and Anna Chrobok ${ }^{2, *}$ \\ 1 Grupa Azoty Zakłady Azotowe Kędzierzyn, S.A., Mostowa 30A, 47-220 Kędzierzyn-Koźle, Poland; \\ Urszula.Dorosz@grupaazoty.com (U.D.); ewa.pankalla@grupaazoty.com (E.P.) \\ 2 Department of Chemical Organic Technology and Petrochemistry, Silesian University of Technology, \\ Krzywoustego 4, 44-100 Gliwice, Poland; natalia.barteczko@polsl.pl (N.B.); piotr.latos@polsl.pl (P.L.); \\ karol.erfurt@polsl.pl (K.E.) \\ * Correspondence: Anna.Chrobok@polsl.pl
}

Received: 30 November 2019; Accepted: 21 December 2019; Published: 27 December 2019

\begin{abstract}
Alkyl lactates are produced from lactic acid via esterification, and are used in the production of plastics, paints, solvents and detergents. In the pursuit of an inexpensive, industry-suitable catalyst for this reaction, the application of protic ionic liquids based on nitrogen base and sulphuric acid is proposed. The ionic liquid was synthesised via a simple reaction of triethylamine and a threefold molar excess of sulphuric acid. Water was added to remove the heat of the reaction. Next, the reaction conditions for the model esterification of 2-ethylhexanol with lactic acid without additional solvent were optimised. Exceptionally mild conditions, i.e., a twofold molar excess of alcohol to lactic acid with the addition of an ionic liquid in a catalytic amount $(15 \mathrm{~mol} \%)$ at $60^{\circ} \mathrm{C}$, resulted in high yields of ethyl and 2-ethylhexyl lactates (96-97\%). The driving force of this reaction is the production of a biphasic system with immiscible ester during the reaction. This phenomenon makes it possible to overcome the reaction equilibrium. Using an inexpensive ionic liquid, which could be recycled up to five times without diminution in conversion or selectivity, leads to both a greener and a more economically-viable process.
\end{abstract}

Keywords: lactate esters; ionic liquids; acidic catalysis; esterification; plasticisers; solvents

\section{Introduction}

Lactic acid (LA) is an important building block for the production of biodegradable polymers, as well as a starting material for the pharmaceutical industry [1]. The current production of LA is dominated by the fermentation of sugars or sugar-containing biomasses. LA is also an important feedstock for the production of alkyl lactates, which are used as raw materials for the manufacturing of many products, such as plastics, paints, solvents and detergents. In recent years, alkyl lactates are increasingly used in food, cosmetics and pharmaceutical formulations due to their hygroscopic, emulsifying and exfoliating properties. In addition, they are known as safe, noncarcinogenic, biodegradable and noncorrosive substances, which are considered green solvents. Their eco-friendly properties have been confirmed by studies in which no toxic or mutagenic effects were observed [1].

Both 2-ethyl-1-hexyl lactate and ethyl lactate are amongst the most useful lactates. As compared to other lactate esters, ethyl lactate has low viscosity, poor volatility and a wide temperature range, ensuring its liquid form as well as good dissolution properties. Therefore, ethyl lactate is widely used in the industry as a solvent, e.g., in the production of microelectronics and semiconductors. It is also used as an additive to paints and cleaning compounds, as it dissolves cellulose and many resins. 
In addition, ethyl lactate is successfully applied in the synthesis of drugs and agrochemicals, and in the production of herbicides [2,3].

In contrast, 2-ethylhexyl lactate does not mix with water and is used in agrochemical concentrates as a rain-resistant emulsifier in the production of anhydrous pesticide preparations [4]. It is also a component of biocides, i.e., agents designed to combat pests in agriculture and forestry. Notably, 2-ethylhexyl lactate is used as a solvent for the production of fungicides (antifungal chemicals) for the protection of plants, as well as being applied as a high-boiling polar solvent for coatings and as a novel solvent in aqueous metal washing processes. In addition, this compound has excellent plasticizing properties, which are being used for the production of green plasticisers [5,6].

$n$-Butyl lactate is mainly used in cosmetics, food and pharmaceutical preparations due to its hygroscopic, emulsifying and exfoliating properties and flavouring effect. It can be also utilised as a solvent for the extraction of 1-butanol from aqueous fermentation broth [7], or as a high-boiling solvent in paint preparations and as a cosurfactant for the preparation of microemulsions with anionic surfactants [8].

Currently, esterification of LA with alcohol is the main method for the industrial production of lactates, utilising homogeneous mineral acids or acidic ion exchange resin as catalysts [9,10]. To improve catalyst recovery and stability, liquid-liquid biphasic catalysis with Brønsted acidic ionic liquids has also been proposed. In this case, it is possible to tune the equilibrium of an esterification reaction using ionic liquids [11-16]. Ionic liquids can play a dual role in the reaction, acting as both the solvent and the catalyst. This system relies on the fact that acid and alcohol are miscible with the ionic liquid, but the resulting ester is insoluble and isolated as a separate phase. This phenomenon shifts the reaction equilibrium strongly towards the product formation. Recovered after simple phase separation, the ionic liquid can be recycled in successive cycles of the reaction.

Only a few examples can be found demonstrating the application of the biphasic system with ionic liquids for the esterification of lactic acid. Acidic ionic liquids, i.e., compounds in the solid state at room temperature composed of propane sulphonate functionalised organic cations and heteropolyanions $\left[\mathrm{PW}_{12} \mathrm{O}_{40}\right]$, were used for the synthesis of $n$-butyl lactate. Ester was obtained with $85 \%$ yield and $100 \%$ selectivity at $110{ }^{\circ} \mathrm{C}$ after $2 \mathrm{~h}$ of reaction. The high melting points of the heteropolyanion-based ionic liquids resulted in the switching from homogeneous to heterogeneous catalysis, which facilitated the separation and recycling of the catalyst [17]. Another example utilises the biphasic system with protic N-methyl-2-pyrrolidoniummethyl sulphonate ionic liquid as a catalyst for the esterification of lactic acid with $n$-butanol. Ester was obtained with $94 \%$ yield with $100 \%$ selectivity at $60{ }^{\circ} \mathrm{C}$ after $4 \mathrm{~h}$ of reaction. Again, the effective recycling of catalysts was demonstrated [18]. In the last example, $\mathrm{SO}_{3} \mathrm{H}$-functionalised Brønsted acidic ionic liquids in an ultrasound-assisted, solvent-free synthesis of $n$-butyl lactate were used. Ester was obtained with $90 \%$ yield at $40{ }^{\circ} \mathrm{C}$ in $4 \mathrm{~h}$ reaction [19].

In this work, in the search for catalysts for lactate production that would be suitable on an industrial scale, we propose an inexpensive Brønsted acidic ionic liquid, together with protic ionic liquids based on nitrogen bases and an excess of sulphuric acid. The ability of the ionic liquids to adopt the dual role of solvent and catalyst was exploited in the esterification of lactic acid with ethanol, butanol and 2-ethylhexanol. This new method can develop into a generic approach to tailoring ionic liquids as a replacement of hazardous acids in industrially-relevant reactions.

\section{Results and Discussion}

Previously, Fischer esterification reactions were carried out in protic ionic liquids with protons located in the cation or anion (Scheme 1) [12-16]. The best results were achieved with ionic liquids based on the $\left[\mathrm{HSO}_{4}\right]^{-}$anion, which was typically used in stoichiometric or higher-than-stoichiometric quantities relative to the starting materials. 


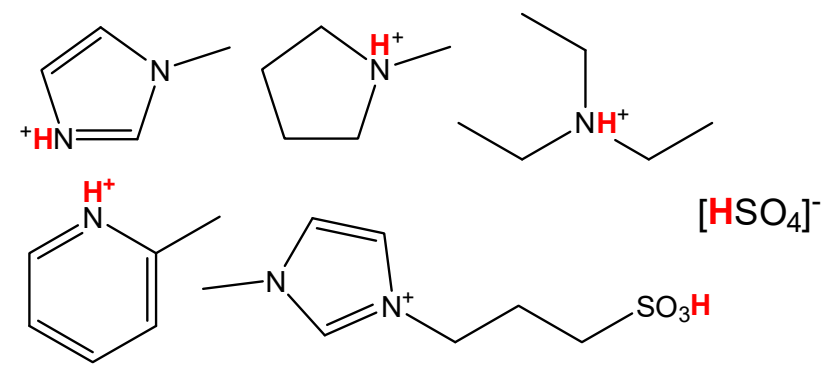

Scheme 1. Location of the proton in cation or anion of the ionic liquid.

The synthesis of protic ionic liquids is based on a simple reaction between a tertiary/aromatic amine and an acid. Using an excess of acid to amine, e.g., sulphuric acid (molar ratio $\chi \mathrm{H}_{2} \mathrm{SO}_{4}=0.67$ and 0.75 ), led to the formation of a hydrogen-bonded network of sulphuric acid molecules and hydrogen sulphate anions in an anion structure $\left[\left(\mathrm{HSO}_{4}\right)\left(\mathrm{H}_{2} \mathrm{SO}_{4}\right) \mathrm{x}\right]^{-}(\mathrm{x}=1$ or 2$)$ with a protonated base (Scheme 2) [12]. Variation of the molar ratio of sulphuric acid, $\chi \mathrm{H}_{2} \mathrm{SO}_{4}$, was used to tune the acidity. Using an excess of sulphuric acid for the synthesis of ionic liquids resulted in the formation of highly acidic liquids at room temperature, in contrast to equimolar mixtures.

$$
\begin{aligned}
& \mathrm{H}_{2} \mathrm{SO}_{4}+\mathrm{B} \rightarrow[\mathrm{HB}]\left[\mathrm{HSO}_{4}\right] \quad \chi \mathrm{H}_{2} \mathrm{SO} 4=0.50 \\
& 2 \mathrm{H}_{2} \mathrm{SO}_{4}+\mathrm{B} \rightarrow[\mathrm{HB}]\left[\left(\mathrm{HSO}_{4}\right)\left(\mathrm{H}_{2} \mathrm{SO}_{4}\right)\right] \quad \chi \mathrm{H}_{2} \mathrm{SO}_{4}=0.67 \\
& 3 \mathrm{H}_{2} \mathrm{SO}_{4}+\mathrm{B} \rightarrow[\mathrm{HB}]\left[\left(\mathrm{HSO}_{4}\right)\left(\mathrm{H}_{2} \mathrm{SO}_{4}\right)_{2}\right] \quad \chi \mathrm{H}_{2} \mathrm{SO} 4=0.75
\end{aligned}
$$

Scheme 2. Synthesis of protic ionic liquids based on sulphuric acid, where B stands for 1-methylpyrrolidine,

1-methylimidazole and trimethylamine, and $\chi$ varied in terms of the molar ratio of sulphuric acid [12].

The production cost of protic ionic liquid based on 1-methylimidazole and equimolar amounts of sulphuric acid on an industrial scale was estimated to be similar to that of ethyl acetate or acetone [20]. In addition, in this work, amine trimethylamine was proposed, which was cheaper than the protic ionic liquid to produce, and a threefold molar excess of sulphuric acid for the synthesis of ionic liquid $\left[\mathrm{Et}_{3} \mathrm{NH}\right]\left[\left(\mathrm{HSO}_{4}\right)\left(\mathrm{H}_{2} \mathrm{SO}_{4}\right)_{2}\right]\left(\chi \mathrm{H}_{2} \mathrm{SO}_{4}=0.75\right)$ was chosen. Quantified acidity of this ionic liquid by Acceptor Number, $\mathrm{AN}=120$ [12], revealed that the acidity was comparable to those other strong acids $\left(\mathrm{AN} \mathrm{CF}_{3} \mathrm{COOH}=105.5, \mathrm{AN} \mathrm{CF}_{3} \mathrm{SO}_{3} \mathrm{H}=129.1\right)$ [21]. Water was added to the synthesis of the ionic liquid in order to remove the heat of the reaction.

First, the solubility of the crucial components of the reaction system was checked. Lactic acid, as well as alcohols (ethanol, 1-butanol, isobutanol and 2-ethylhexanol), and water were miscible with ionic liquid. Esters posed a potential problem, with only 2-ethylhexyl lactate being immiscible with ionic liquids. Therefore, the esterification of lactic acid with 2-ethylhexanol was chosen as a model reaction (Scheme 3).<smiles>CCC(CC#CC#CC(C)C(=O)OCC(CC)CCC[18OH])CCCCOC(=O)C(C)O</smiles>

Scheme 3. The model reaction for the esterification of lactic acid with 2-ethylhexanol.

The model esterification was carried out at $60{ }^{\circ} \mathrm{C}$ with a twofold excess of 2-ethylhexanol to lactic acid. Decane, as an internal standard for GC measurements, was added to the reactor in the process in which reaction kinetics was determined. The processes carried out for product isolation 
proceeded without the addition of decane. Various amounts of the catalyst (5-50\%, expressed as mol\% per lactic acid) were used to determine the optimum catalyst loading (Figure 1). In all cases, after several minutes of the reaction, first, the turbidity and, finally, the creation of the biphasic system were observed (Scheme 4). Using $30 \mathrm{~mol} \%$ of ionic liquid resulted in a high yield of 2-ethylhexyl lactate after $60 \mathrm{~min}$. In fact, higher amounts of ionic liquid (50 mol\%) did not significantly influence the reaction rate, clearly showing the saturation point as well as a plateau in the activity. In contrast, smaller amounts of ionic liquid ( $5 \mathrm{~mol} \%$ ) were insufficient. The most promising results, conjoining the yield and economic aspects, were achieved for $15 \mathrm{~mol} \%$ of ionic liquid ( $97 \%$ yield after $180 \mathrm{~min}$ ). For comparison, the reaction was also carried out in the presence of $15 \mathrm{~mol} \%$ of the catalyst at $40^{\circ} \mathrm{C}$ (Figure 1). Nevertheless, the yield was lower than in other cases, even after $300 \mathrm{~min}$. These initial studies confirmed that the biphasic system works efficiently.

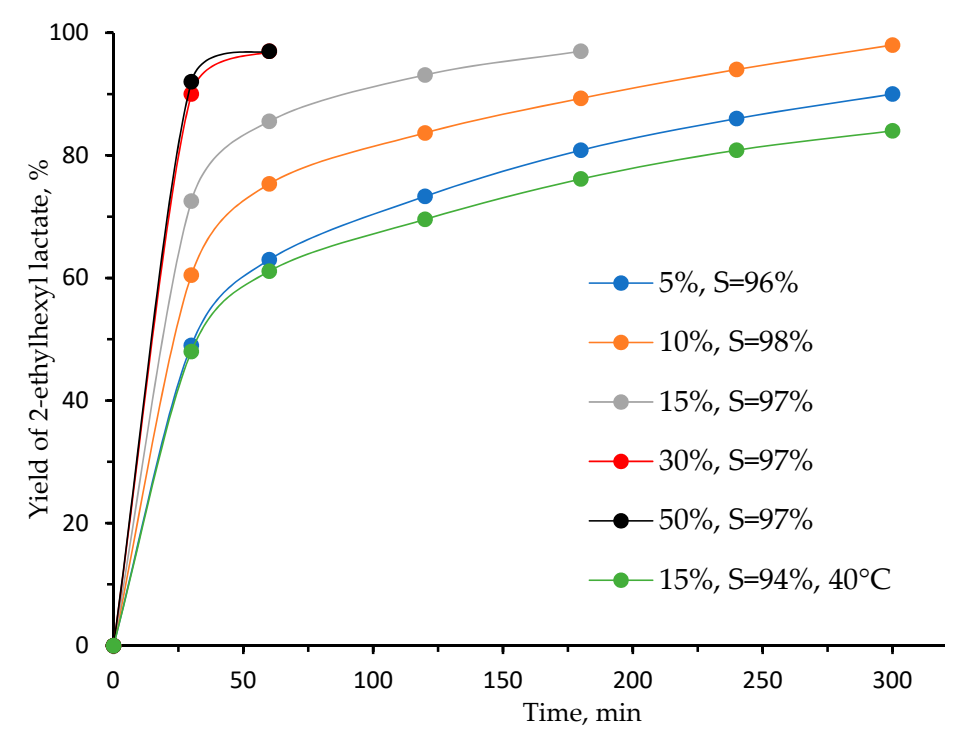

Reaction conditions: 2-etylohexanol (130.23 g, $1.00 \mathrm{~mol})$, lactic acid (45.04 g, $0.50 \mathrm{~mol})$, [Et $3 \mathrm{NH}]\left[\left(\mathrm{HSO}_{4}\right)\left(\mathrm{H}_{2} \mathrm{SO}_{4}\right)_{2}\right]$, $60{ }^{\circ} \mathrm{C}, 900 \mathrm{rpm}$. Yields and selectivities were determined by GC; all experiments were triplicated (standard deviation $1 \%)$.

Figure 1. The influence of catalyst loading on the yield of 2-ethylhexyl lactate.

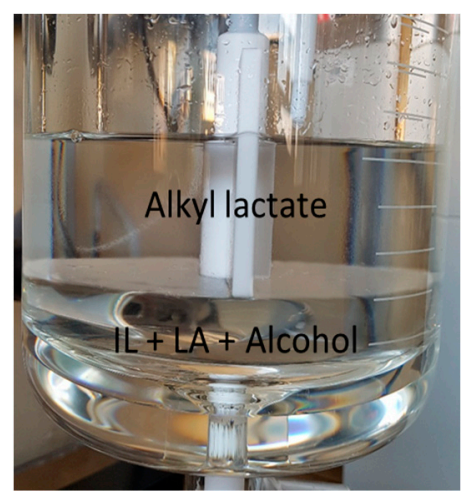

Scheme 4. Photograph of the reactor with the postreaction mixture of model esterification of lactic acid with 2-ethylhexanol (IL-ionic liquid).

Lactic acid has a bifunctional character; it contains a hydroxyl group connected with the carboxylic acid, so it can undergo spontaneous intermolecular esterification in aqueous solutions with concentrations higher than $20 \%$. A linear dimer and higher acid oligomers are formed, and the degree of mutually esterified lactic acid molecules increases, together with its concentration. For example, 
$88 \%$ lactic acid solution contains $43.5 \mathrm{~mol} \%$ of monomer, $9.2 \mathrm{~mol} \%$ of dimer, $1.8 \mathrm{~mol} \%$ of trimer and $45 \mathrm{~mol} \%$ of water [2], which makes the use of lactic acid complicated as a substrate for the esterification reaction. Using a high concentration of lactic acid implies the presence of lactic acid oligomers during esterification, which convert into the corresponding esters and further undergo hydrolysis and transesterification. Altogether, the process leads to the formation of mixtures of monomers and oligomers of acid and esters.

During the process, other byproducts may also be formed, such as cyclic dimers of lactic acid (lactides) and the resulting ester with the second ester molecule or lactic acid. Thus, it is crucial to carefully choose the conditions of the reaction, to ensure that not only conversion, but also selectivity are as high as possible. Figure 1 shows the selectivity obtained in each reaction (94-98\%). The only byproduct observed on GC was the esterified dimer of lactic acid.

The influence of the ratio of the reactants on the reaction rate and the final yield of 2-ethylhexyl lactate was studied at $60{ }^{\circ} \mathrm{C}$, using $15 \mathrm{~mol} \%$ of $\left[\mathrm{Et}_{3} \mathrm{NH}\right]\left[\left(\mathrm{HSO}_{4}\right)\left(\mathrm{H}_{2} \mathrm{SO}_{4}\right)_{2}\right]$ (Figure 2). Using an excess of one of the reactants is also a tool to shift the esterification equilibrium. As expected, using higher amounts of 2-ethylhexanol (from the molar ratio of acid to alcohol 1:1 to 1:4) resulted in higher reaction rates with a high yield of ester, as well as in higher selectivity ( $98 \%$ for $4: 1)$. A total of $50 \mathrm{~mol} \%$ of alcohol was not enough to achieve a high yield. The twofold molar excess of alcohol enabled the synthesis of ester in $96 \%$ yield after $3 \mathrm{~h}$.

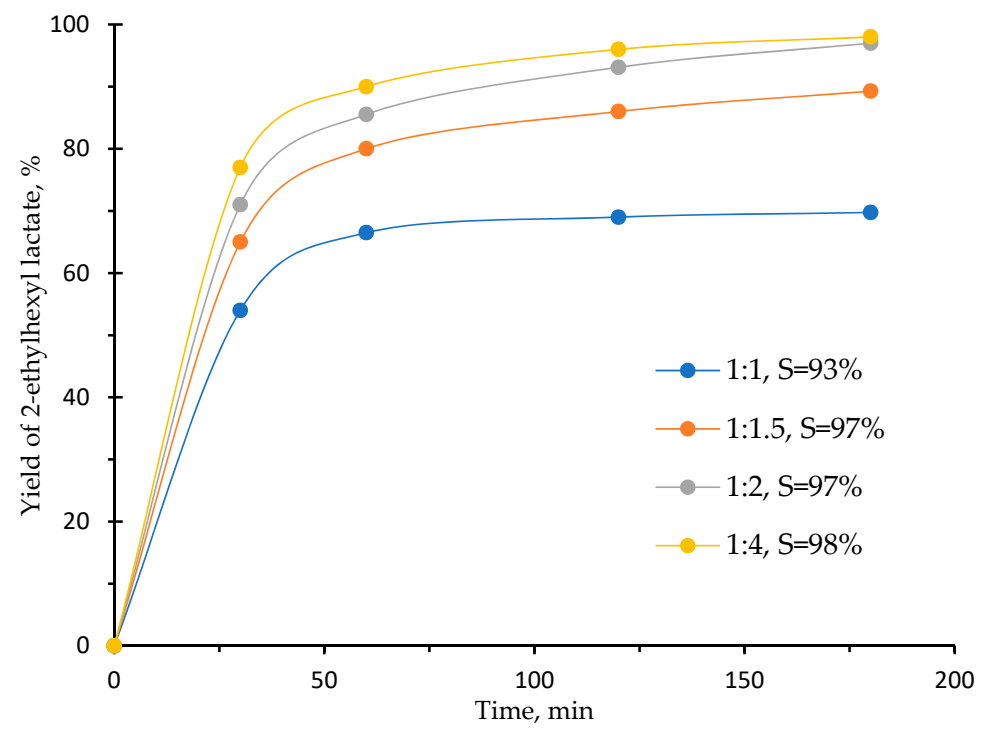

Reaction conditions: 2-etylohexanol, lactic acid (45.04 g, $0.50 \mathrm{~mol})$, [ $\left.\mathrm{Et}_{3} \mathrm{NH}\right]\left[\left(\mathrm{HSO}_{4}\right)\left(\mathrm{H}_{2} \mathrm{SO}_{4}\right)_{2}\right](15 \mathrm{~mol} \%$ per lactic acid, $23.73 \mathrm{~g}, 0.075 \mathrm{~mol}), 60^{\circ} \mathrm{C}, 900 \mathrm{rpm}$. Yields and selectivities were determined by GC; all experiments were triplicated (standard deviation $1 \%$ ).

Figure 2. The influence of the ratio of the reactants on the yield of 2-ethylhexyl lactate.

Other alcohols were also used for the esterification of lactic acid, i.e., ethanol, $n$-butanol and isobutanol, and the results of the esterification were compared with the esterification of 2-ethylhexanol (Figure 3). For the synthesis of 2-ethylhexyl lactate, poor solubility of the ester product in the ionic liquid layer causes phase separation, driving the equilibrium towards the product formation, which resulted in the overcoming of esterification equilibrium and the high yield of product in relatively short reaction time. It was not possible to design a biphasic system based on butyl and ethyl esters, as they are miscible with ionic liquids. The system stays homogenous during the reaction, and in case of the formation of butyl esters, the reaction only slightly overcomes the equilibrium. To illustrate this phenomenon, the synthesis of $n$-butyl lactate with $\mathrm{H}_{2} \mathrm{SO}_{4}$ was also performed. The same reaction rate was observed with around $50 \%$ yield limited by the formation of reaction equilibrium (Figure 3 ). However, ethyl lactate was obtained in $96 \%$ yield after $1.5 \mathrm{~h}$ of reaction. The wide range of industrial 
applications of ethyl lactate increases the opportunity of additional applicability of this method for the production of ethyl lactate.

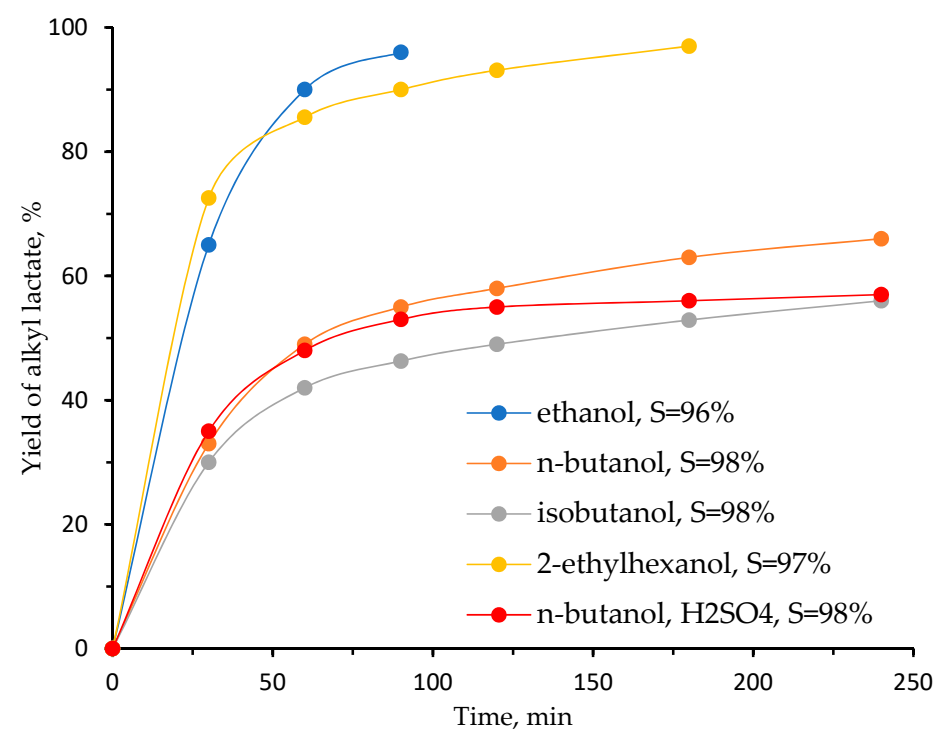

Reaction conditions: alcohol (1.00 mol), lactic acid (45.04 g, $0.50 \mathrm{~mol})$, [Et3 $\mathrm{NH}]\left[\left(\mathrm{HSO}_{4}\right)\left(\mathrm{H}_{2} \mathrm{SO}_{4}\right)_{2}\right](15 \mathrm{~mol} \%$ per lactic acid, $23.73 \mathrm{~g}, 0.075 \mathrm{~mol}), 60{ }^{\circ} \mathrm{C}, 900 \mathrm{rpm}$. Yields and selectivities were determined by GC; all experiments were triplicated (standard deviation $1 \%$ ).

Figure 3. The influence of the alcohol structure on the yield of ester.

Finally, to demonstrate the stability of the catalyst, recycling of ionic liquid was analysed under the following reaction conditions: $60^{\circ} \mathrm{C}, 30 \mathrm{~mol} \%$ of $\left[\mathrm{Et}_{3} \mathrm{NH}\right]\left[\left(\mathrm{HSO}_{4}\right)\left(\mathrm{H}_{2} \mathrm{SO}_{4}\right)_{2}\right.$. After each catalytic run, the product was decanted from over the ionic liquid layer, and unreacted starting materials with water were removed from the ionic liquid solution by vacuum distillation. In five consecutive runs, almost no mass loss of the ionic liquid was observed (up to 1-2 mass\%). The yield of ester, although appearing to decline slightly, remained within the error bars of the measurement for all five runs (mean yield $=98 \%$, Figure 4 ).

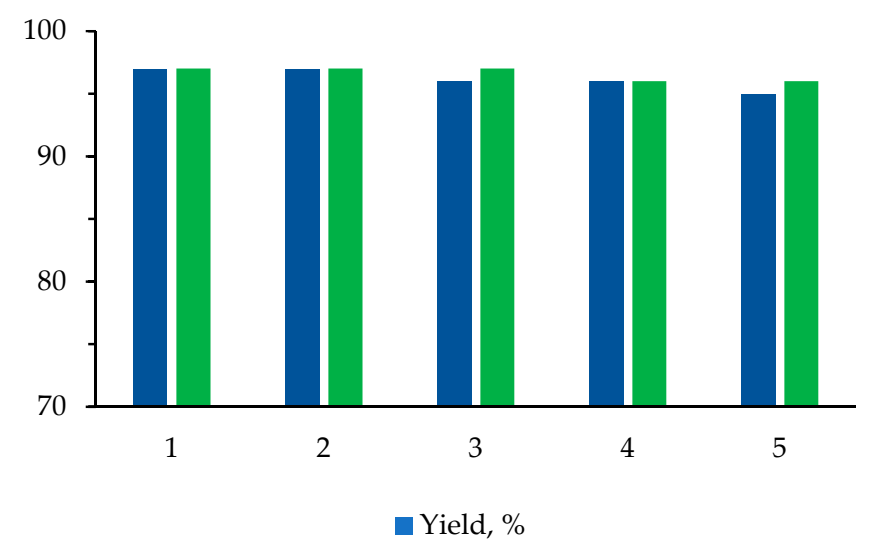

Reaction conditions: 2-ethylhexanol (1.00 mol), lactic acid (45.04 g, $0.50 \mathrm{~mol})$, [ $\left.\mathrm{Et}_{3} \mathrm{NH}\right]\left[\left(\mathrm{HSO}_{4}\right)\left(\mathrm{H}_{2} \mathrm{SO}_{4}\right)_{2}\right](30 \mathrm{~mol} \%$ per lactic acid, $23.73 \mathrm{~g}, 0.075 \mathrm{~mol}), 60{ }^{\circ} \mathrm{C}, 900 \mathrm{rpm}$, reaction time $1 \mathrm{~h}$. Yields and selectivities were determined by GC; all experiments were triplicated (standard deviation $1 \%$ ).

Figure 4. Studies. 


\section{Materials and Methods}

\subsection{Materials}

Triethylamine, sulphuric acid (95\%), D,L-lactic acid (85\%), n-butanol, isobutanol, ethanol, 2-ethylhexanol and decane were all purchased from Sigma-Aldrich, Poznan, Polska) and used as received.

\subsection{Synthesis}

Protic ionic liquid [Et $3 \mathrm{NH}]\left[\left(\mathrm{HSO}_{4}\right)\left(\mathrm{H}_{2} \mathrm{SO}_{4}\right)_{2}\right]$ : triethylamine $(25.30 \mathrm{~g}, 0.25 \mathrm{~mol}, 1 \mathrm{~mol}$ eq. $)$ was placed in a jacketed glass reactor $(250 \mathrm{~mL})$, equipped with a temperature probe, a cooling condenser and a mechanical stirrer. The required amount of sulphuric acid (77.43 g, $0.75 \mathrm{~mol}, 3 \mathrm{~mol} \mathrm{eq.)} \mathrm{as} \mathrm{a}$ solution in water $(10.27 \mathrm{~g}, 0.57 \mathrm{~mol})$ was added dropwise with vigorous stirring (110 rpm, $20 \mathrm{~min}$, $40{ }^{\circ} \mathrm{C}$ ), and then the mixture was stirred for $1 \mathrm{~h}$ at room temperature. Subsequently, the ionic liquid produced was dried under high vacuum $\left(80^{\circ} \mathrm{C}, 10-2 \mathrm{bar}\right.$, overnight). Ionic liquid was obtained with $98 \%$ yield as a colourless liquid. $1 \mathrm{H} \mathrm{NMR}(400 \mathrm{MHz}, \mathrm{DMSO}) \delta 8.95(\mathrm{~s}, 1 \mathrm{H}), 7.51(\mathrm{bs}, 5 \mathrm{H}), 3.07(\mathrm{kw}, 6 \mathrm{H}$, $J=6.4 \mathrm{~Hz}), 1.15$ (t, 9H, $J=7.9 \mathrm{~Hz})$. 13C NMR (151 MHz, DMSO) $\delta 48.02,12.20$.

Alkyl lactates: [ $\left.\mathrm{Et}_{3} \mathrm{NH}\right]\left[\left(\mathrm{HSO}_{4}\right)\left(\mathrm{H}_{2} \mathrm{SO}_{4}\right)_{2}\right](47.46 \mathrm{~g}, 0.15 \mathrm{~mol}, 15 \mathrm{~mol} \%)$, alcohol (46.07-130.23 g, $1.00 \mathrm{~mol}$ ), lactic acid (45.04 g, $0.50 \mathrm{~mol}$, molar ratio of acid to alcohol 1:2) and decane (as internal standard, $3 \mathrm{~g}$ ) were placed in a jacketed glass reactor $(250 \mathrm{~mL})$, equipped with a temperature probe, a cooling condenser and a mechanical stirrer. The reaction mixture was stirred at $60{ }^{\circ} \mathrm{C}$ for $1-4 \mathrm{~h}$. Every $30 \mathrm{~min}$, the sample was collected from the reactor from the upper phase to measure the progress of the reaction using GC. After the reaction was completed, the phases were separated. The upper phase was mixed with hexane $(20 \mathrm{~mL})$, extracted with water $(3 \times 20 \mathrm{~mL})$ and washed with a saturated solution of $\mathrm{NaHCO}_{3}(10 \mathrm{~mL})$ to remove the traces of ionic liquid. Next, after drying with anhydrous $\mathrm{MgSO}_{4}$, the organic phase was concentrated on a rotary evaporator. After distillation, the alcohol was removed at $63-65{ }^{\circ} \mathrm{C}(10 \mathrm{mmHg})$ for 2-ethylhexanol and $78-81^{\circ} \mathrm{C}$ for ethanol.

A $97 \%$ yield $(98.11 \mathrm{~g})$ of 2-ethylhexyl lactate as a colourless liquid was obtained. 1H NMR (400 MHz, DMSO) $\delta 5.29(\mathrm{~d}, J=5.7 \mathrm{~Hz}, 1 \mathrm{H}), 4.14-4.03(\mathrm{~m}, 1 \mathrm{H}), 4.02-3.82(\mathrm{~m}, 2 \mathrm{H}), 1.57-1.43(\mathrm{~m}, 1 \mathrm{H})$, $1.44-1.32(\mathrm{~m}, 1 \mathrm{H}), 1.42-1.04(\mathrm{~m}, 11 \mathrm{H}), 0.92-0.70(\mathrm{~m}, 6 \mathrm{H})$.

Ethyl lactate was obtained as a colourless liquid with $96 \%$ yield $(56.70 \mathrm{~g}) .1 \mathrm{H} \mathrm{NMR}(400 \mathrm{MHz}$, $\mathrm{CDCl} 3) \delta 4.27(\mathrm{~m}, 1 \mathrm{H}), 4.21(\mathrm{q}, J=7.1 \mathrm{~Hz}, 2 \mathrm{H}), 3.1(\mathrm{bs}, 1 \mathrm{H}), 1.42(\mathrm{~m}, 3 \mathrm{H}), 1.29(\mathrm{t}, J=7.1 \mathrm{~Hz}, 3 \mathrm{H})$.

\subsection{Recycling Studies}

The reaction was carried out at $60{ }^{\circ} \mathrm{C}$ with $30 \mathrm{~mol} \%$ of $\left[\mathrm{Et}_{3} \mathrm{NH}\right]\left[\left(\mathrm{HSO}_{4}\right)\left(\mathrm{H}_{2} \mathrm{SO}_{4}\right)_{2}\right.$. After each catalytic run, the product was decanted from over the ionic liquid layer, and unreacted starting materials and water were removed from the ionic liquid by vacuum distillation. In addition, the ionic liquid was dried under a high vacuum $\left(80^{\circ} \mathrm{C}, 10-2\right.$ bar, overnight).

\section{Conclusions}

In this study, we showed that using protic ionic liquid as the acidic catalyst and solvent enables the esterification of lactic acid with unexpectedly high efficiency. Moreover, ionic liquids were easily prepared from trimethylamine and sulphuric acid at very low cost. The key development of our study was using a threefold molar excess of sulphuric acid (molar ratio $\chi \mathrm{H}_{2} \mathrm{SO}_{4}=0.75$ ), which led to the formation of a hydrogen-bonded network of sulphuric acid molecules and hydrogen sulphate anions in anion structure $\left[\mathrm{Et}_{3} \mathrm{NH}\right]\left[\left(\mathrm{HSO}_{4}\right)\left(\mathrm{H}_{2} \mathrm{SO}_{4}\right)_{2}\right.$. The acidity of the formed ionic liquid was relatively high, compared to other strong acids such as $\mathrm{CF}_{3} \mathrm{COOH}$ and $\mathrm{CF}_{3} \mathrm{SO}_{3} \mathrm{H}$.

Several alcohols were used for the esterification of lactic acid: ethanol, 2-ethylhexanol, $n$-butanol and isobutanol. Using a twofold molar excess of alcohol to lactic acid at $60{ }^{\circ} \mathrm{C}$, a high yield of 2-etylhexyl and ethyl lactates (96-97\%) was obtained. The primary advantage of using ionic liquid over the classical catalyst, i.e., sulphuric acid, was the production of the biphasic system during the 
reaction, which caused a shift in the equilibrium of esterification. The insolubility of ester is a key parameter for the success of this method, and in case of the synthesis of butyl lactates, it is necessary to find a nonmiscible acidic ionic liquid.

Ionic liquid prepared from triethylamine and sulphuric acid was not only inexpensive, but also easily recycled multiple times without significant loss of activity. Using $30 \mathrm{~mol} \%$ excess of ionic liquid, it was possible to consistently achieve yields above $95 \%$ under exceptionally mild conditions. The economic advantages of this method are the possibility to obtain a high yield of the product in one reaction cycle and the recyclable catalytic system. The purification process based on phase separation, alkaline washing of the organic phase and distillation is similar to the classical industrial methods for the production of esters. Our results demonstrate both an environmentally- and economically-sustainable process with strong potential of industrial implementation.

Author Contributions: Data collection regarding the synthesis of esters, U.D.; data collection and contribution to the manuscript writing, N.B.; data collection regarding the synthesis of ionic liquid, P.L.; data analysis and interpretation, K.E.; Writing-Original draft preparation, E.P.; conceptualisation, data analysis and interpretation, contribution to the manuscript writing, A.C. All authors have read and agreed to the published version of the manuscript.

Funding: This research was funded by the company Grupa Azoty Zakłady Azotowe Kedzierzyn S.A.

Conflicts of Interest: The authors declare no conflict of interest.

\section{References}

1. Shuklov, I.A.; Dubrovina, N.V.; Kühlein, K.; Börner, A. Chemo-catalyzed pathways to lactic acid and lactates. Adv. Synth. Catal. 2016, 358, 3910-3931. [CrossRef]

2. Pereira, C.S.; Silva, V.M.; Rodrigues, A.E. Ethyl lactate as a solvent: Properties, applications and production processes-A review. Green Chem. 2011, 13, 2658-2671. [CrossRef]

3. Aparicio, S.; Alcalde, R. Insights into the ethyl lactate + water mixed solvent. J. Phys. Chem. B 2009, 113, 14257-14269. [CrossRef] [PubMed]

4. Figoli, A.; Marino, T.; Simone, S.; Di Nicolò, E.; Li, X.-M.; He, T.; Tornaghi, S. Towards non-toxic solvents for membrane preparation: A review. Green Chem. 2014, 16, 4034-4059. [CrossRef]

5. Randová, A.; Bartovská, L.; Morávek, P.; Matějka, P.; Novotná, M.; Matějková, S.; Drioli, E.; Figoli, A.; Lanč, M.; Friess, K. A fundamental study of the physicochemical properties of Rhodiasolv ${ }^{\circledR}$ Polarclean: A promising alternative to common and hazardous solvents. J. Mol. Liq. 2016, 224, 1163-1171. [CrossRef]

6. Baur, P.; Davies, L.E.; Pontzen, R.; Rochling, A. Use of Lactate Esters for Improving the Action of Agricultural Pesticides. U.S. Patent 2008/03 18791 A1, 25 December 2018.

7. Zheng, S.; Chen, L.; Chen, L.; Qi, Z. Feasibility of bio-based lactate esters as extractant for biobutanol recovery: (Liquid + liquid) equilibria. J. Chem. Thermod. 2016, 93, 127-131. [CrossRef]

8. Kumar, R.; Mahajani, S.M. Esterification of lactic acid with n-butanol by reactive distillation. Ind. Eng. Chem. Res. 2007, 46, 6873-6882. [CrossRef]

9. Pereira, C.S.; Pinho, S.P.; Silva, V.M.; Rodrigues, A.E. Thermodynamic equilibrium and reaction kinetics for the esterification of lactic acid with ethanol catalyzed by acid ion-exchange Resin. Ind. Eng. Chem. Res. 2008, 47, 1453-1463. [CrossRef]

10. Sanz, M.T.; Murga, R.; Beltran, S.; Cabezas, J.L. Autocatalyzed and ion-exchange-resin-catalyzed esterification kinetics of lactic acid with methanol. Ind. Eng. Chem. Res. 2002, 41, 512-517. [CrossRef]

11. Kar, M.; Matuszek, K.; MacFarlane, D.R. Ionic Liquids in Kirk-Othmer Encyclopedia of Chemical Technology; John Wiley \& Sons: Hoboken, NJ, USA, 2019. [CrossRef]

12. Matuszek, K.; Chrobok, A.; Coleman, F.; Seddon, K.R.; Swadźba-Kwaśny, M. Tailoring ionic liquid catalysts: Structure, acidity and catalytic activity of protonic ionic liquids based on anionic clusters, [(HSO4)(H2SO4)x] - $(\mathrm{x}=0,1$, or 2). Green Chem. 2014, 16, 3463-3471. [CrossRef]

13. Chiappe, C.; Rajamani, S.; D'Andrea, F. A dramatic effect of the ionic liquid structure in esterification reactions in protic ionic media. Green Chem. 2013, 15, 137-143. [CrossRef] 
14. Tao, D.J.; Wu, Y.T.; Zhou, Z.; Geng, J.; Hu, X.B.; Zhang, Z.B. Kinetics for the esterification reaction of n-butanol with acetic acid catalyzed by noncorrosive Brønsted acidic ionic liquids. Ind. Eng. Chem. Res. 2011, 50, 1989-1996. [CrossRef]

15. Belieres, J.P.; Angell, C.A. Protic ionic liquids: preparation, characterization, and proton free energy level representation. J. Phys. Chem. B 2007, 111, 4926-4937. [CrossRef] [PubMed]

16. Yoshizawa, M.; Xu, W.; Angell, C.A. Ionic liquids by proton transfer: Vapor pressure, conductivity, and the relevance of $\Delta \mathrm{pKa}$ from aqueous solutions. J. Am. Chem. Soc. 2003, 125, 15411-15419. [CrossRef] [PubMed]

17. Leng, Y.; Wang, J.; Zhu, D.; Ren, X.; Ge, H.; Shen, L. Heteropolyanion-based ionic liquids: Reaction-induced self-separation catalysts for esterification. Angew. Chem. 2009, 121, 174-177. [CrossRef]

18. Zhang, H.; Xu, F.; Zhou, X.; Zhang, G.; Wang, C. A Brønsted acidic ionic liquid as an efficient and reusable catalyst system for esterification. Green Chem. 2007, 9, 1208-1211. [CrossRef]

19. Li, X.; Lin, Q.; Ma, L. Ultrasound-assisted solvent-free synthesis of lactic acid esters in novel SO3H-functionalized Brønsted acidic ionic liquids. Ultrason. Sonochem. 2010, 17, 752-755. [CrossRef] [PubMed]

20. George, A.; Brandt, A.; Tran, K.; Zahari, S.M.S.N.S.; Klein-Marcuschamer, D.; Sun, N.; Sathitsuksanoh, N.; Shi, J.; Stavila, V.; Parthasarathi, R.; et al. Design of low-cost ionic liquids for lignocellulosic biomass pretreatment. Green Chem. 2015, 17, 1728-1734. [CrossRef]

21. Gutmann, V. The Donor-Acceptor Approach to Molecular Interactions; Plenum Press: New York, NY, USA, 1978.

(C) 2019 by the authors. Licensee MDPI, Basel, Switzerland. This article is an open access article distributed under the terms and conditions of the Creative Commons Attribution (CC BY) license (http://creativecommons.org/licenses/by/4.0/). 